\title{
Cultural Collisions, a cross disciplinary science education format
}

\author{
Michael Hoch \\ HEPHY, Austrian Academy of Science (AT), \\ Nikolsdorfergasse 18, 1050 Vienna, Austria \\ E-mail: Michael.Hoch@cern.ch
}

"Cultural Collisions" is a cross-disciplinary science and art engagement and networking program with special emphasis on educational methodologies. It is designed to trigger curiosity, creativity, and foster critical thinking in school students to help them overcome the scientific and technological challenges of the 21 st century.

The Cultural Collisions format has been implemented and tested in several European countries - Austria, Germany, Switzerland, Montenegro and recently in the Czech Republic. During ICHEP2020 the final student artworks of Cultural Collisions Czech will be presented. Furthermore, it was the key component of a research project sponsored by the Ontario Ministry of Education, Canada, which assessed the educational impact on participating students. In the presentation, cross-disciplinary methodologies will be discussed and results will be presented. The evaluation shows that the programme demonstrated its capacity to increase motivation and interest in science via creative science engagement and increased the educational outcome.

The format was developed and evaluated within the EU funded project CREATIONS, the CMS experiment at CERN and recently by the ORIGIN collaboration. ORIGIN is a cooperation of scientific collaborations working on the secrets of the origin of the universe in the fields of particle physics, gravitational waves, neutrino physics, cosmology and astrophysics, which supports interdisciplinary science engagement.

40th International Conference on High Energy physics - ICHEP2020

July 28 - August 6, 2020

Prague, Czech Republic (virtual meeting) 


\section{Introduction}

Cultural Collisions is an innovative, interdisciplinary experience designed for teachers and students to explore the possibilities for learning when the arts and sciences are integrated. As a means of reconceptualising traditional models of interdisciplinary education, Cultural Collisions facilitates combining multiple perspectives between the arts and science in order to create an environment where thinking and learning transform into merging perspectives, strategies, tools and skills in order to discover the science in art and the art in science.

Cultural Collisions is an education and networking format that allows students to gain authentic and personal access to scientific fields and scientific communities while they are approaching complex topics through artistic practices. By contact and networking with people who are active in the respective fields, a lasting impact is generated for all participants involved. The overall goal is to present science as a creative activity and the arts as a serious examination of the subject matter.

Science\&Art@School is a cross disciplinary science and art education project format which was introduced in 2013 for Austrian schools in Graz and Vienna. It is the predecessor format from which Cultural Collisons developed and was presented at the 14th ICATPP conference [1]. Both formats have been developed at CERN by the international particle physics collaboration CMS within the art@CMS [2] program supported by the H2020 EU program CREATIONS [3]. They successfully demonstrated how to inspire the world's next generation and to foster creativity and a critical thinking process. These formats are interdisciplinary in their character and involve teachers from the fields of science (e.g. physics) and the arts or music to work together. Because they focus on creative expression in scientific topics, language and music teachers may also participate.

The scientific support for the Cultural Collisions projects has been provided by the ORIGIN network. ORIGIN is a cooperation of international science collaborations - ALICE, ATLAS, CMS, LHCb, LIGO, VIRGO and ICEcube.

\section{The Cultural Collisions format follows a sequence in $\mathbf{3}$ phases:}

Phase 1; A visit to a dedicated interdisciplinary science and art exhibition. This exhibition acts as framework in which to provide lectures and run workshops on scientific and arts topics. Scientific staff and artists giving lectures and running the workshops is essential to provide authenticity for the students. The purpose is to facilitate and guide the students to be able to follow up with their own research on the scientific topics and inspire them with creative expressions of the topics. This event serves as an initial spark that will allow students to engage for phase 2.

Phase 2; Creative follow up and process at school. During the weeks and months after visiting the interdisciplinary science and art exhibition, the art teachers follow up the creative process with the students and help them to develop their own artwork. Some schools include this interdisciplinary investigation into a 'Theory of Knowledge' course. In this setting, the art teachers take on the role of the principle dialog partner and the physics teachers act as supervisor for the science topics. Optional digital tools may be offered to the participating students like a 'Virtual Visit' [5] to an experimental site or an online "rehearsal and ideas exchange session" via a standard video conferencing system.

Phase 3; Final exhibition of the student artworks in a public venue.

For the final presentation of the student artworks or performances, it is important to find a prominent public place to recognise the engagement of all participants, students and teachers. An additional option is to build in a competition and reward selected exceptional contributions. In various national projects in Europe, Asia and North America, students created impressive creative records of their investigation that demonstrated their deep involvement in and understanding of the scientific subject and the overall creative process. 


\section{Partner selection for cross-disciplinary projects:}

To guarantee the success of an interdisciplinary project it is important that professional partners from all fields are involved. In addition to scientist, artists and cultural mediators dedicated educators are crucial for the successful implementation of the program. In the Cultural Collisions Vienna project, the art education department of the mumok (Museum of Modern Culture Vienna) is offering art and science dialog sessions and hands on workshops over a full day. During the Cultural Collisions Canada project scientists, artists, and musicians were giving lectures and running workshops including rap music, data sonification, science masterclass, and construction of a cloud chamber, colour experiment, science flash mob and other activities.

\section{Evaluation}

\section{Report by the Ministry of Education Ontario, Canada 2018}

A professional independent evaluation of the Cultural Collisons - Canada 2018 event was conducted by the Ministry of Education Ontario. The principle findings were:

\section{a. General assesment}

Cultural Collisions - Canada was an innovative, interdisciplinary experience for teachers and students to explore the possibilities for learning when the arts and sciences were integrated. As a means of reconceptualising traditional models of disciplinary education. Cultural Collisions allowed for the infusion of multiple perspectives between the arts and science in order to create an environment where thinking and learning became about melding perspectives, strategies, tools and skills in order to see the science in and of art and the art in science.

Diversity of voice and perspective create the conditions for rich thinking and learning. Disciplines in the "science, technology, engineering and applied math", so called STEM fields such as physics and engineering continue to struggle with increasing diversity and inclusion. In order to encourage underrepresented student groups to consider STEM career pathways, and to help foster a more STEM adept society, Cultural Collisions wanted to provide opportunities for learning that: (i) demystified STEM subjects (ii) provided experiences that were inclusive, authentic and connected to the lived realities around students. Students must be inspired to wonder and ask questions. A goal of this project was to provide students the opportunity to take learning from a variety of subjects and apply them into new contexts, in an integrated way, while developing transferable skills that would enable them to solve complex problems.

Collected feedback indicates that students found the learning meaningful and engaging in a different way positively to their daily school experiences in science. Responses such as "This experience was better, more interactive, more developed/going deeper than school activities" and "This was more practical, more interactive [than school], Training from scientists seems more real, more credible" speaks to the success of the project meeting a goal of providing an authentic and realistic experience.

\section{b. Student and Teacher 'feed forward' on Cultural Collisions}

Teachers were also pleased to express their uttermost admiration for what the Cultural Collisions project aimed to accomplish, as it held the ability to help students unpack the biases students may have had in regards to science learning, "The Arts and Cultural Collisions project has been really good at breaking down barriers for our kids unconscious biases and assumptions they have in their head about what is science and what is art. I think it has been really good at helping them look at scientists as human beings able to perform and act in society, just like how they see artists responding to question from society. Seeing that parallel has been really helpful." Breaking Down Barriers Collaboration between teachers and professionals of a variety of disciplines also allowed for professional learning beyond our own training.

The responses demonstrate that there is a clear and necessary role for cross-curricular integration of subject specific content as a means of supporting student engagement and learning. 
Participants of the Cultural Collisions project gained and changed perspectives about the possibilities for understanding and knowledge acquisition when presented with learning in integrated and immersive ways. Students were easily able to demonstrate their knowledge by providing in-depth explanations of concepts using specific terminology and definitions. Making connections to personal experiences and real-world realities, using analogies and engaging in inquiry, students were able to clearly demonstrate their learning.

\section{Conclusions}

The Cultural Collisions format has been implemented successfully in various countries in Europe, North America and Asia in recent years. Cross disciplinary science engagement and networking formats like Science\&Art@School or Cultural Collisions make the case for forms of education that foster skills that are more appropriate to the challenges of the $21^{\text {st }}$ century. These formats are built on networking and authentic collaborations with specialists in the corresponding fields, science and the arts. They aim to act like an ideas factory on a platform of learning, sharing and sustainable development. They are a form of learner's hub where the individual can take ownership of their ideas and can share them with others.

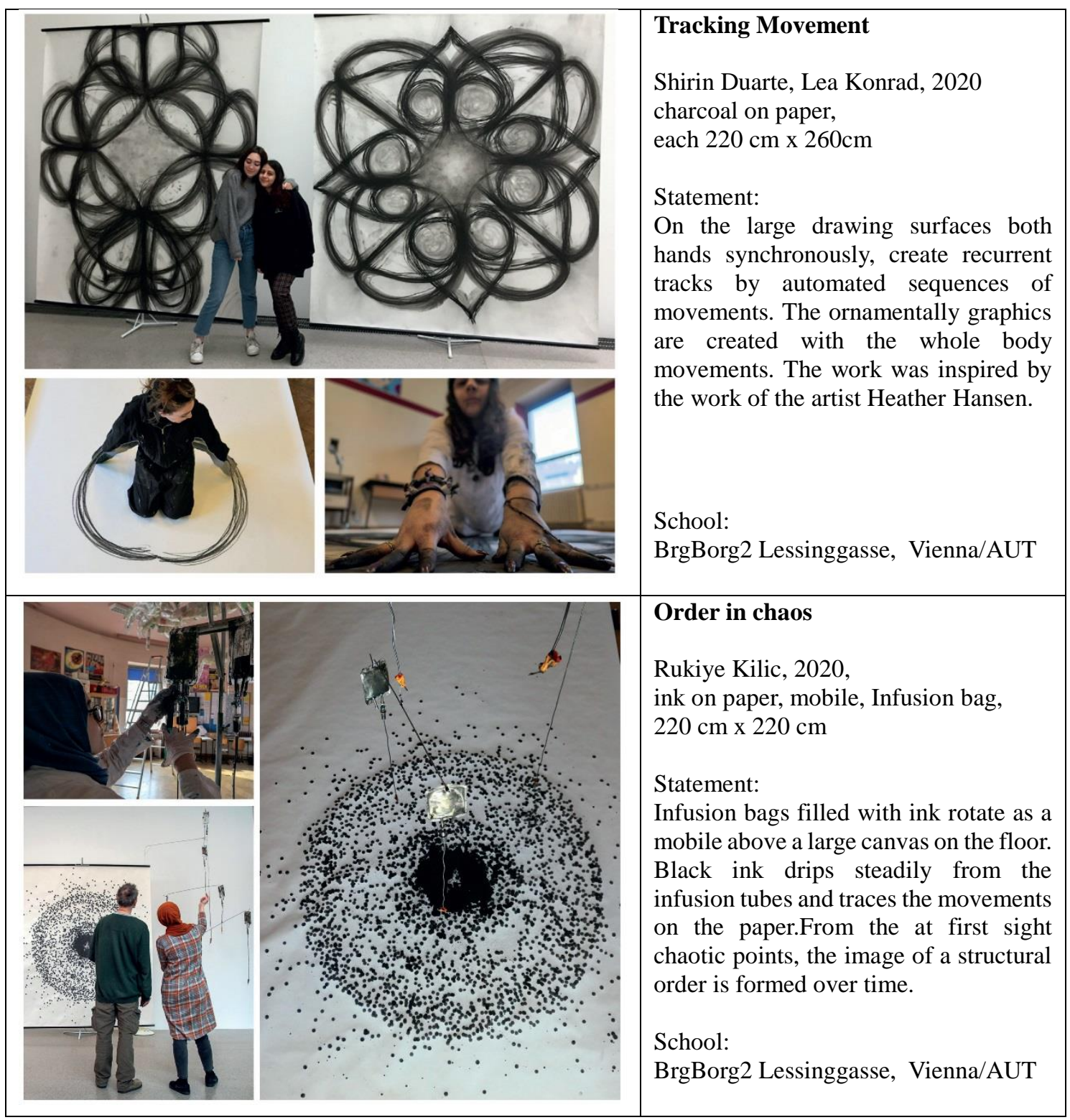


Based on the impact created the following awards have been achieved recently:

- REALM 2020, Category: Education Innovation; Ontario Canada,

- Science Communication Award 2020, Royal Flemish Academy of Belgium for Science and the Arts

- European Physical Society Prize 2017 "for initiatives highlighting the conceptual and physical beauty of high-energy physics, and the inspirational qualities that are common to both Art and Science"

\section{References}

[1] M. Hoch, “ART@CMS and SCIENCE\&ART@SCHOOL: Novel Education and Communication Channels for Particle Physics", Proceedings of the $14^{\text {th }}$ ICATPP Conference, Vol.1 728-736 (2013)

[2] Hoch, M., Alexopoulos, A., Preece, S., Storr, M. and Petrilli, A. “art@CMS SciArt Workshops", 38th International Conference on High Energy Physics, Chicago, 3-10 August (2016)

[3] H2020 EU funded project CREATIONS - Developing an Engaging Science Classroom; http://creations-project.eu/

[4] Paolucci, P., Alexopoulos, A., Hoch. M., \& Adam-Bourdarios, C. LHCP 2016, "STEAM: Education and Communication with Art at ATLAS and CMS", Fourth Annual LHCP conference. Lund, June 13-18 June (2016)

[5] Aguirre L., Adam-Bourdarios C., Alexopoulos A., Beni N., Goldfarb S., Hoch M., Lapka M.,Petrilli A., Zsillasi Z. "ATLAS and CMS Virtual Visits: Bringing Cutting Edge Science into the Classroom and Beyond". The EPS2015 Conference on High Energy Physics, Vienna 22-29 July (2015) 